\title{
First results from the
}

\section{$3^{\text {rd }}$ Level of the}

H1 Fast Track Trigger

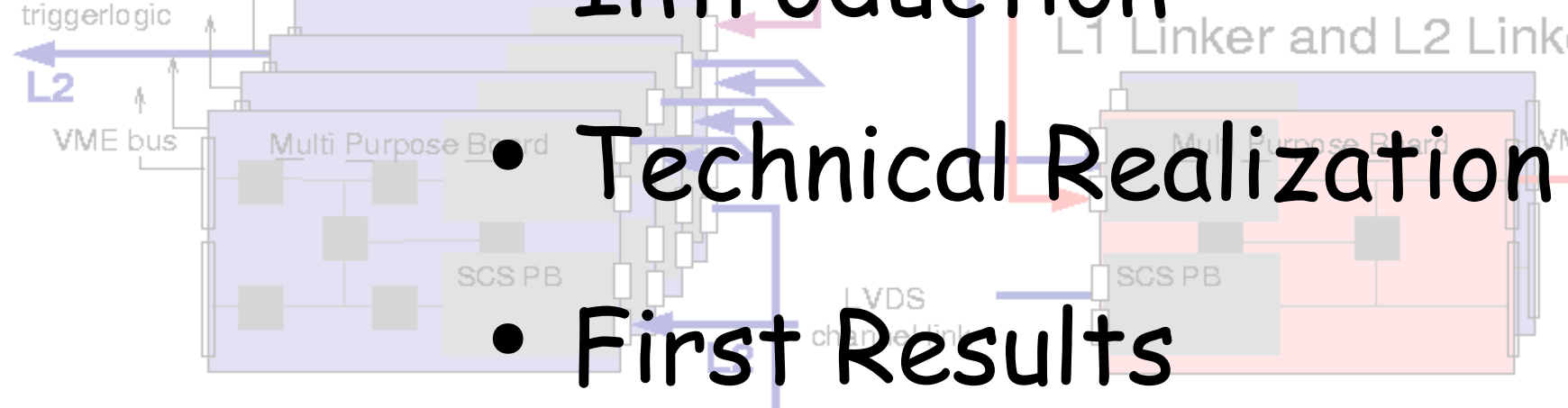

\section{pqzp, zVtx, tracks for L3}

A.W.Jung, A. Baird, R. Baldinger, S. Baumgartner, D. Beneckenstein, N. Berger,

M.-O. Boenig, D.P. Brown, L. Caminada, D. Dodt, E. Elsen, Y.H. Fleming,

M. Kolander, S.Kolya, K. Krüger, K. Lohwasser, D. Meer, D. Mercer, V. Michels, D. Müller, J.

Müller, J. Naumann, P.R. Newman, D.P.C. Sankey, M. Sauter, A. Schöning,

H.-C. Schultz-Coulon, M. Wessels, Ch. Wissing, W. Yan 


\section{(iii) H1-detector@ HERAII}

Electron-Proton Collider: $\sqrt{s} \approx 320 \mathrm{GeV}$

$E(e)=27.5 \mathrm{GeV}$

$E(p)=920 \mathrm{GeV}$

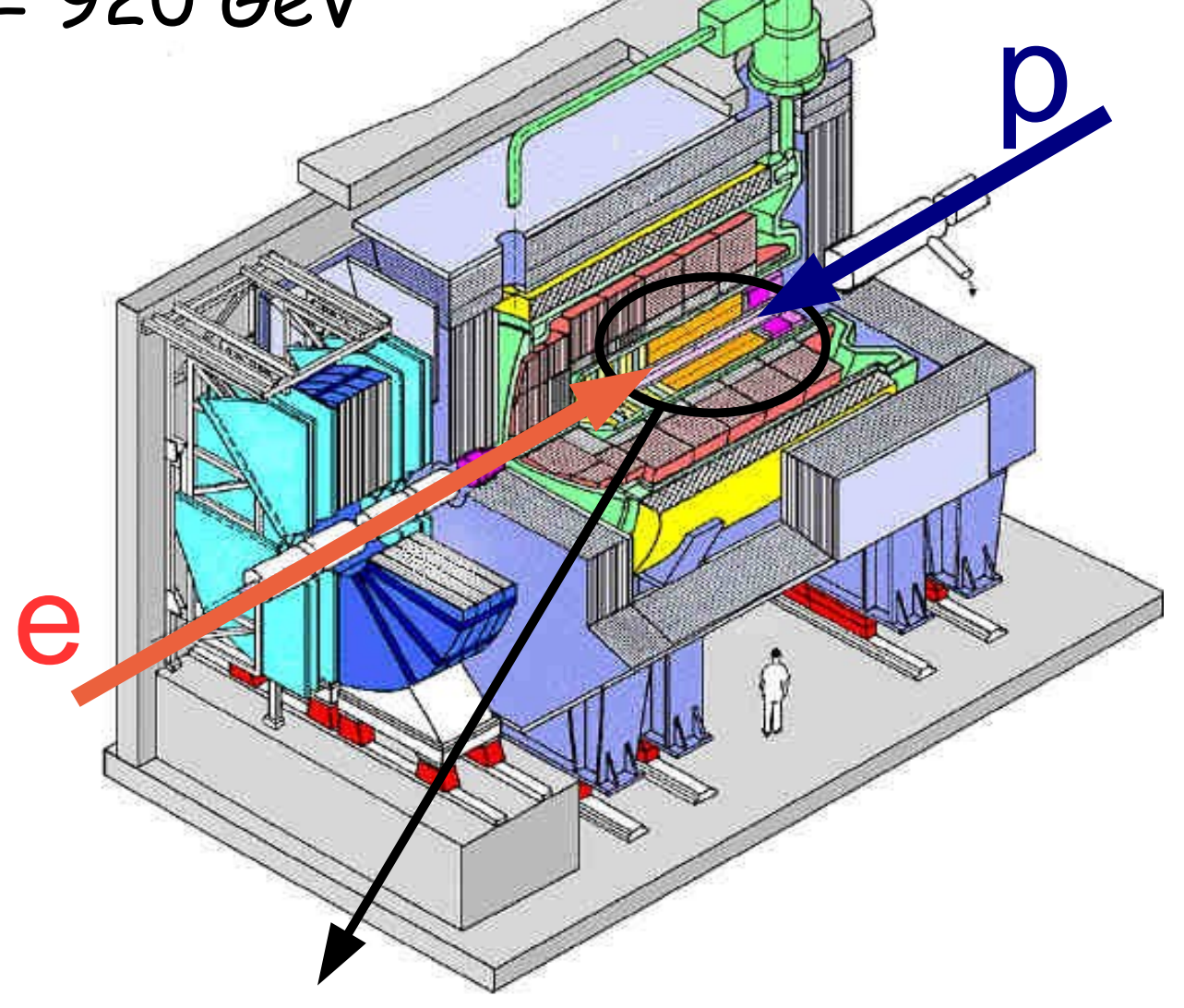

Central Jet Chambers 1 \& 2

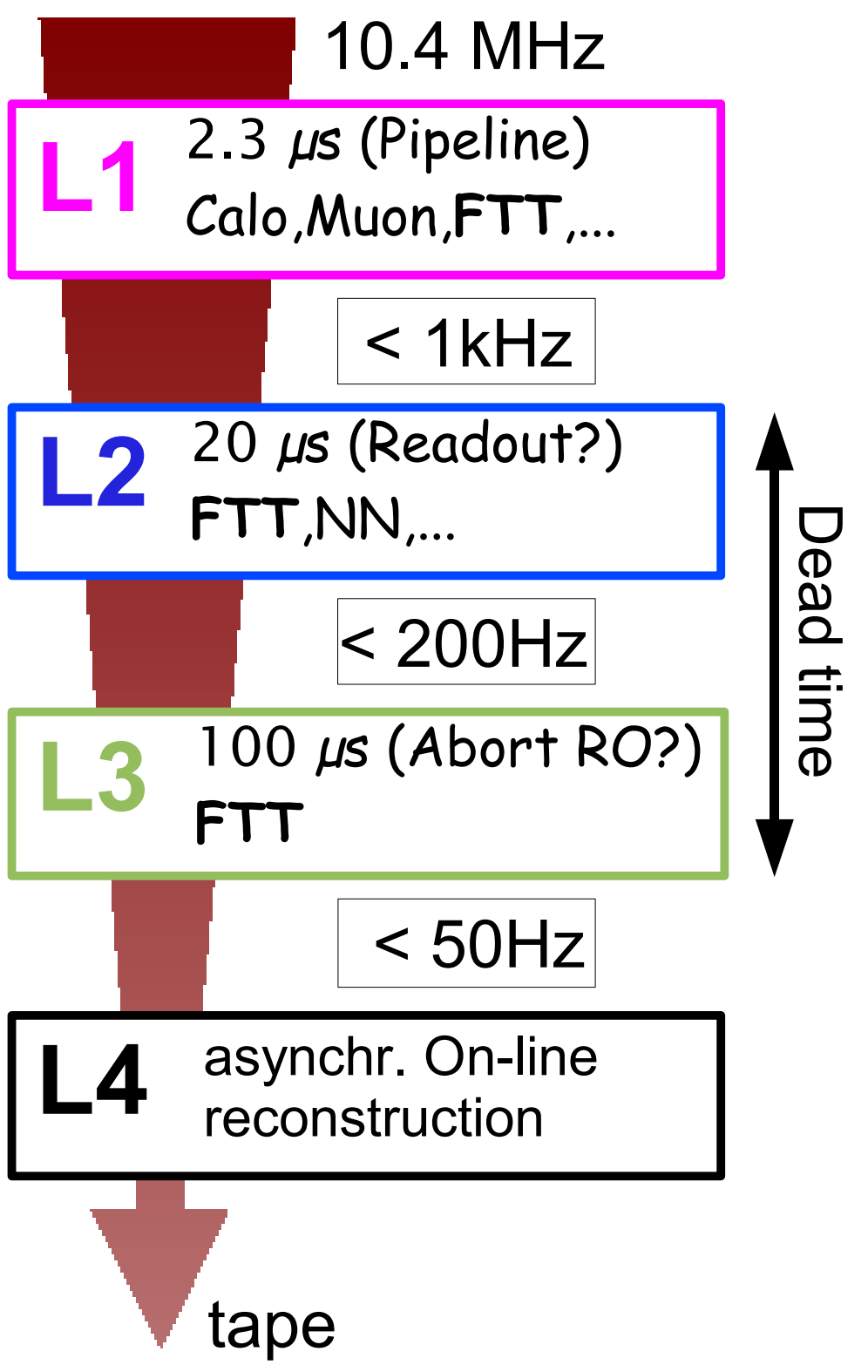

May $1^{\text {st }}, 2007$ First results from the $3^{\text {rd }}$ level of the H1 Fast Track Trigger (FTT) 


\section{(1iin) FTT: the concept}

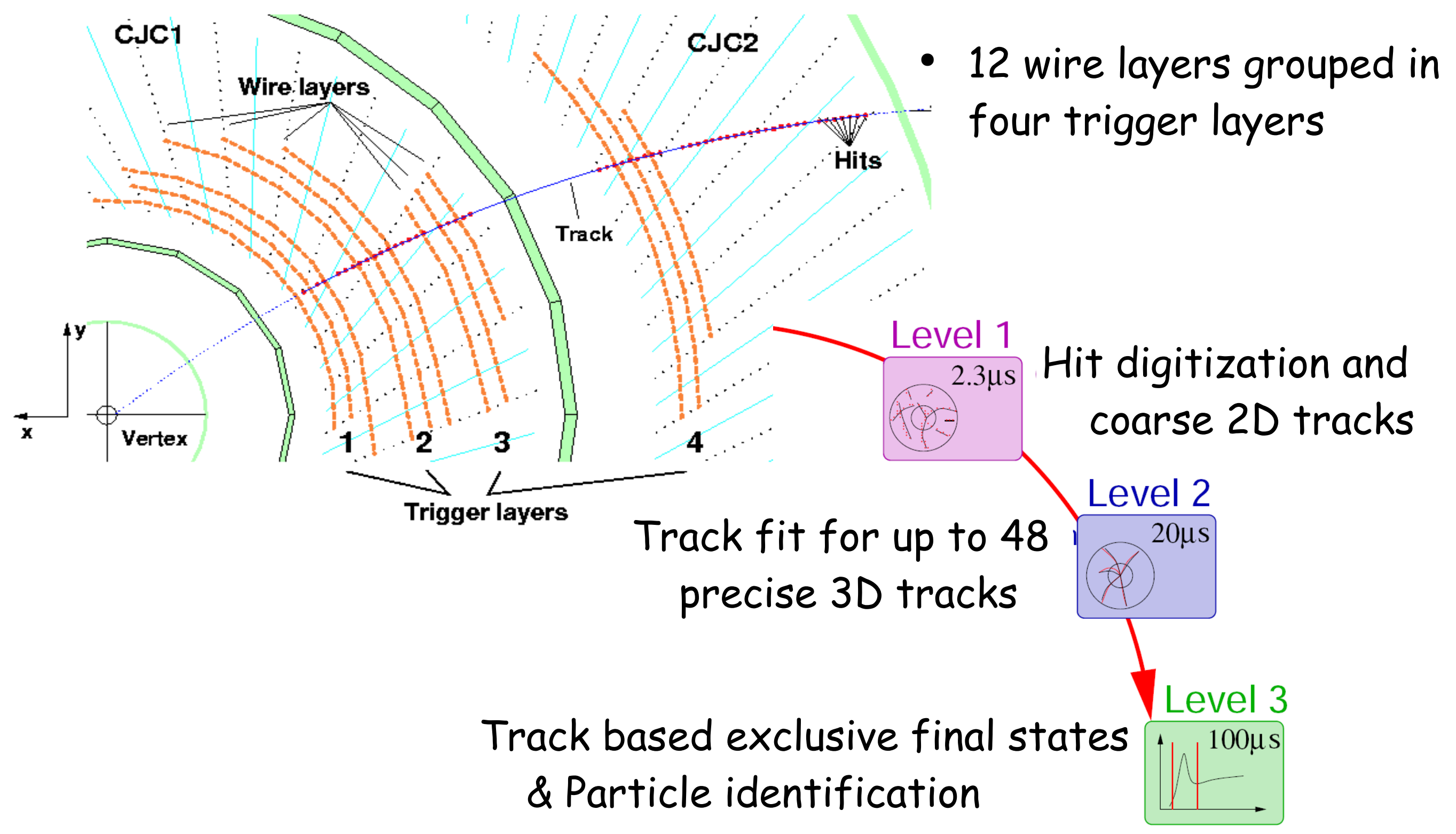




\section{(1ii) FTT - L1 \& L2: key parameters}

FTT-L1: - tracks with $\mathrm{p}_{\mathrm{T}}>100 \mathrm{MeV}$

FTT-L2: - up to 48 precise 3D tracks in $20 \mu \mathrm{s}:$

$\sigma\left(1 / \mathrm{p}_{T}\right)=2 \% / \mathrm{GeV}$

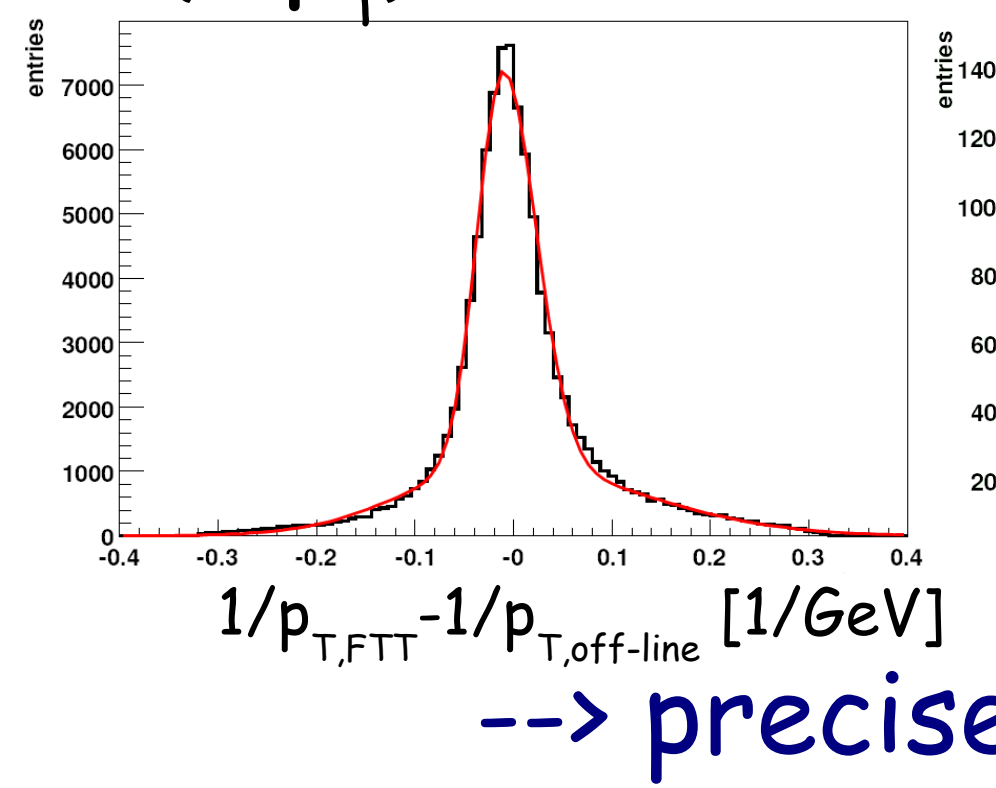

May $1^{\text {st }}, 2007$ $\sigma(\phi)=2.4 \mathrm{mrad}$

$\sigma(\theta)=50 \mathrm{mrad}$
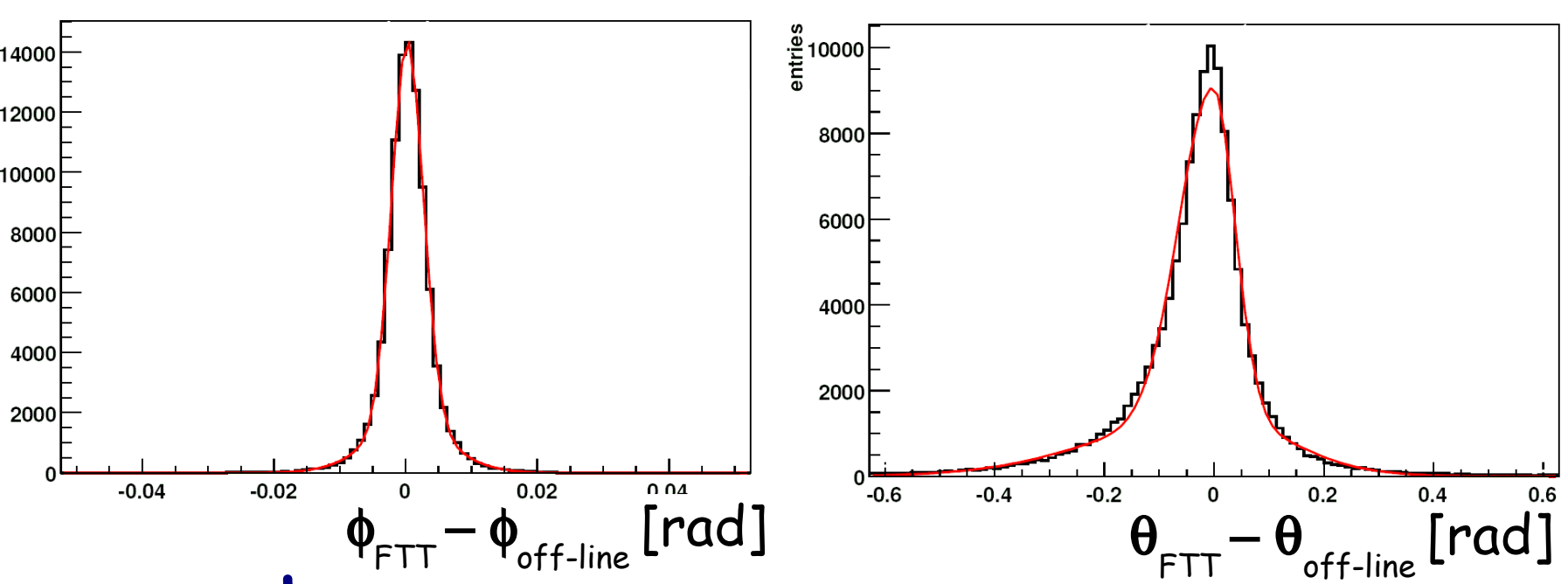

track parameters 


\section{FTT-L3: motivation}

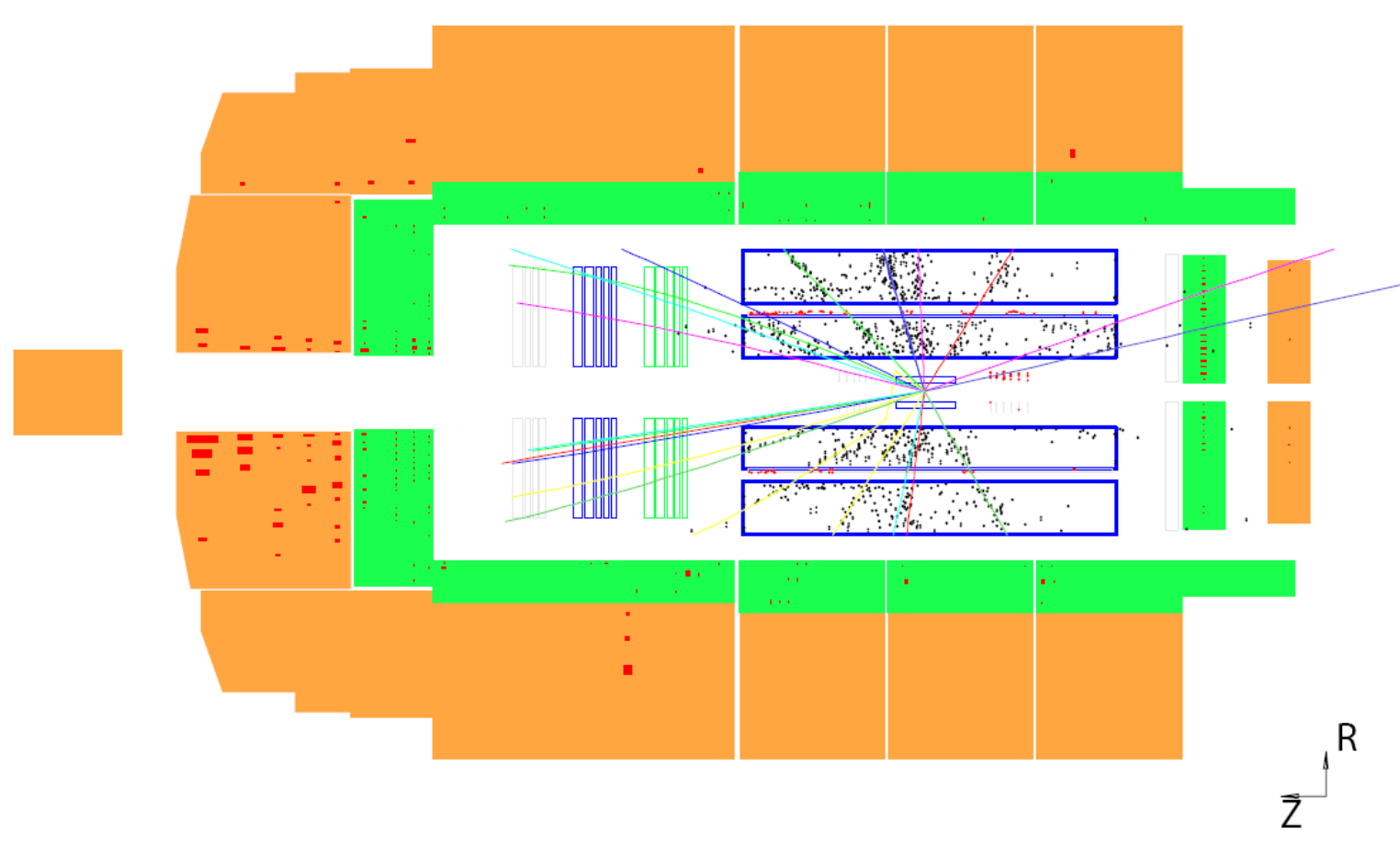

- Photoproduction (largest ep X-section)

- Rare track based final states (c- \& b-quarks)

FTT- L3 input data:

- FTT-L2

Fast!

L3 trigger decision:

- invariant mass hypotheses

- Other: Calorimeter- and

- Combination of Subsystem Muon data informations (particle ID) 


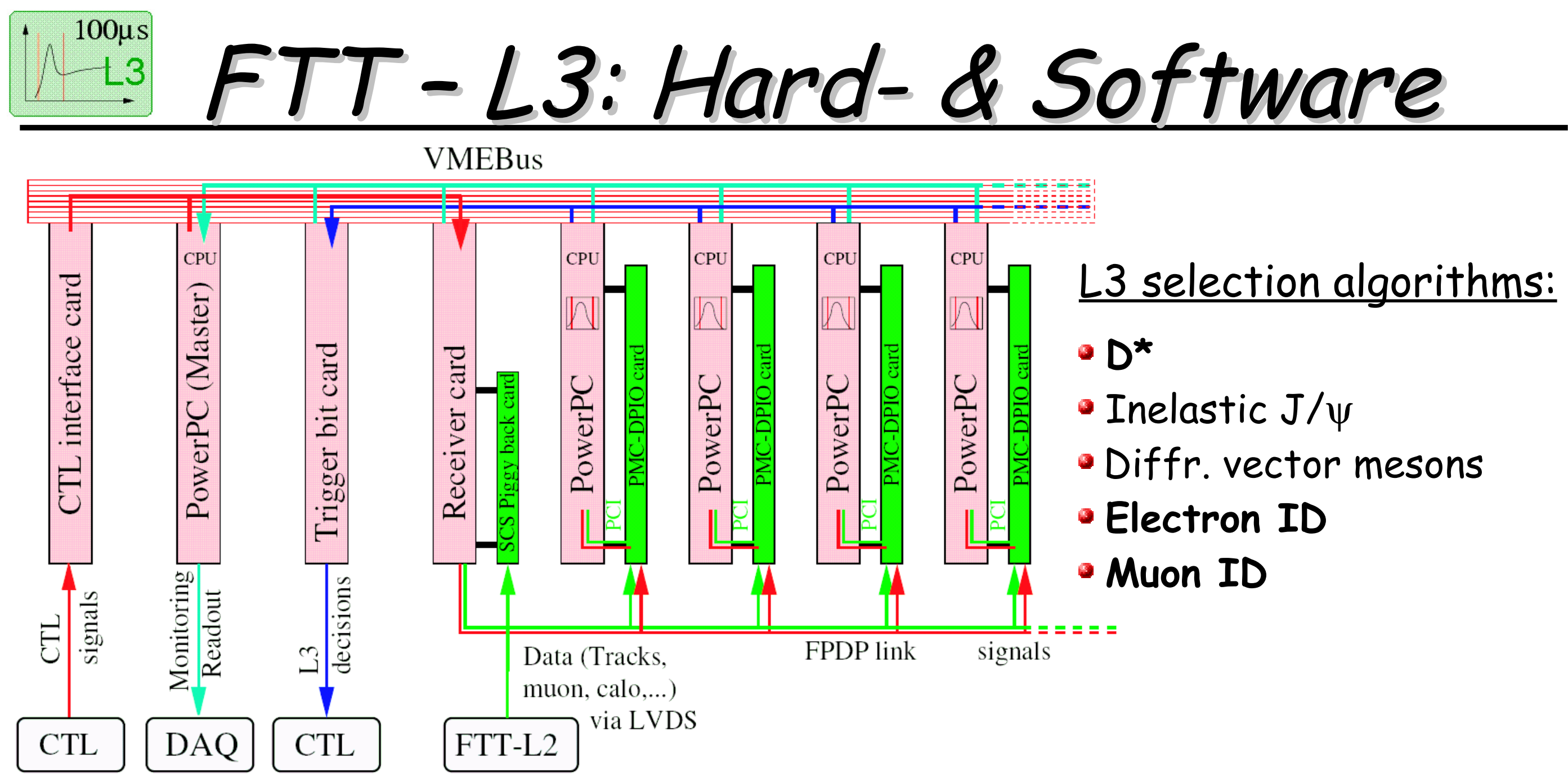

- 5 (up to 16) PowerPC (VME G3/G4 - processor cards)

- Front Panel Data Port: simultaneous data transfer to PowerPCs

- Real time OS "vxWorks" 
D* selection algorithm:

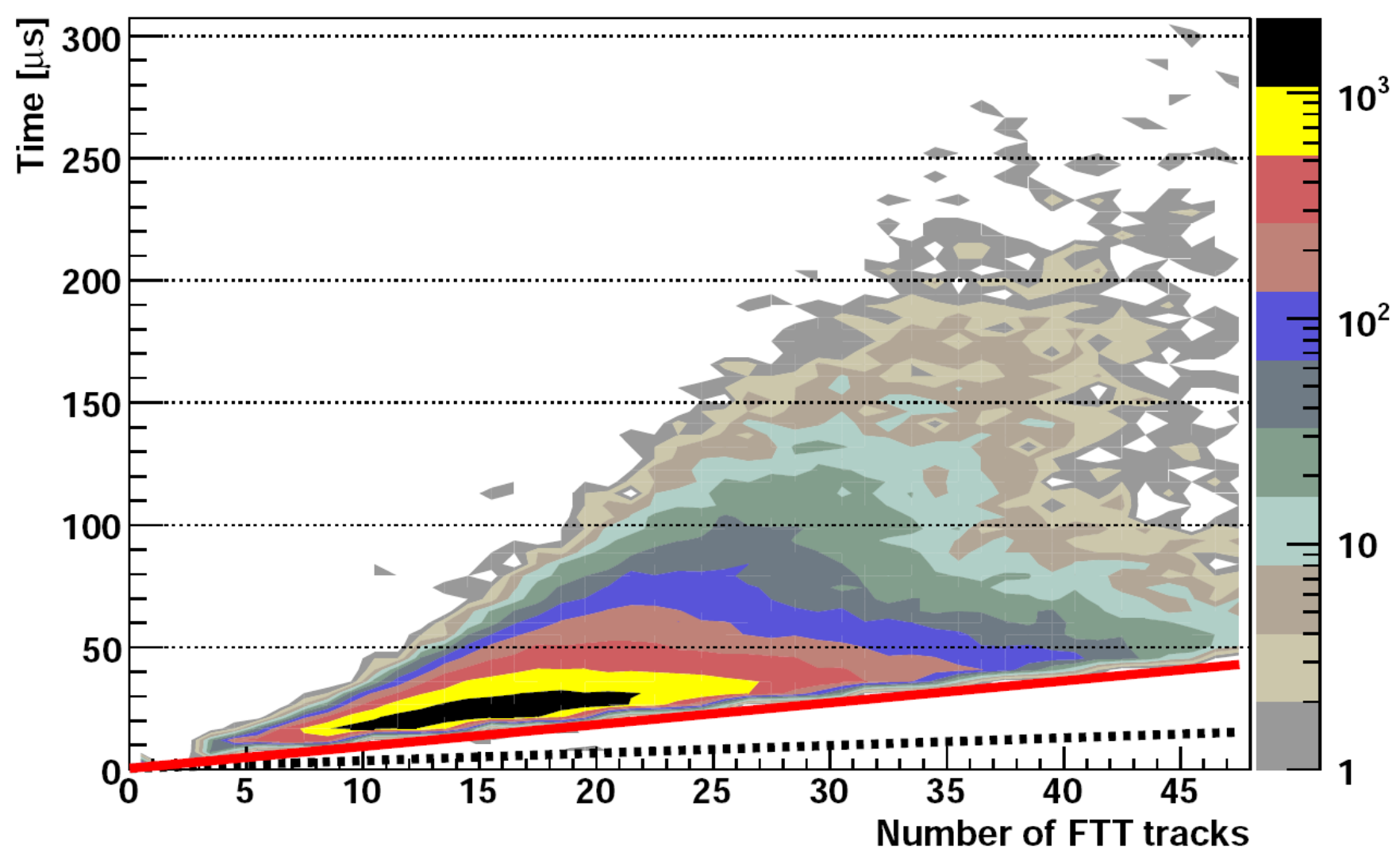

--> fast enough for $97 \%$ of the events
Trigger decision

Data preparation $<40 \mu s$

Data transfer

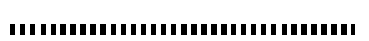




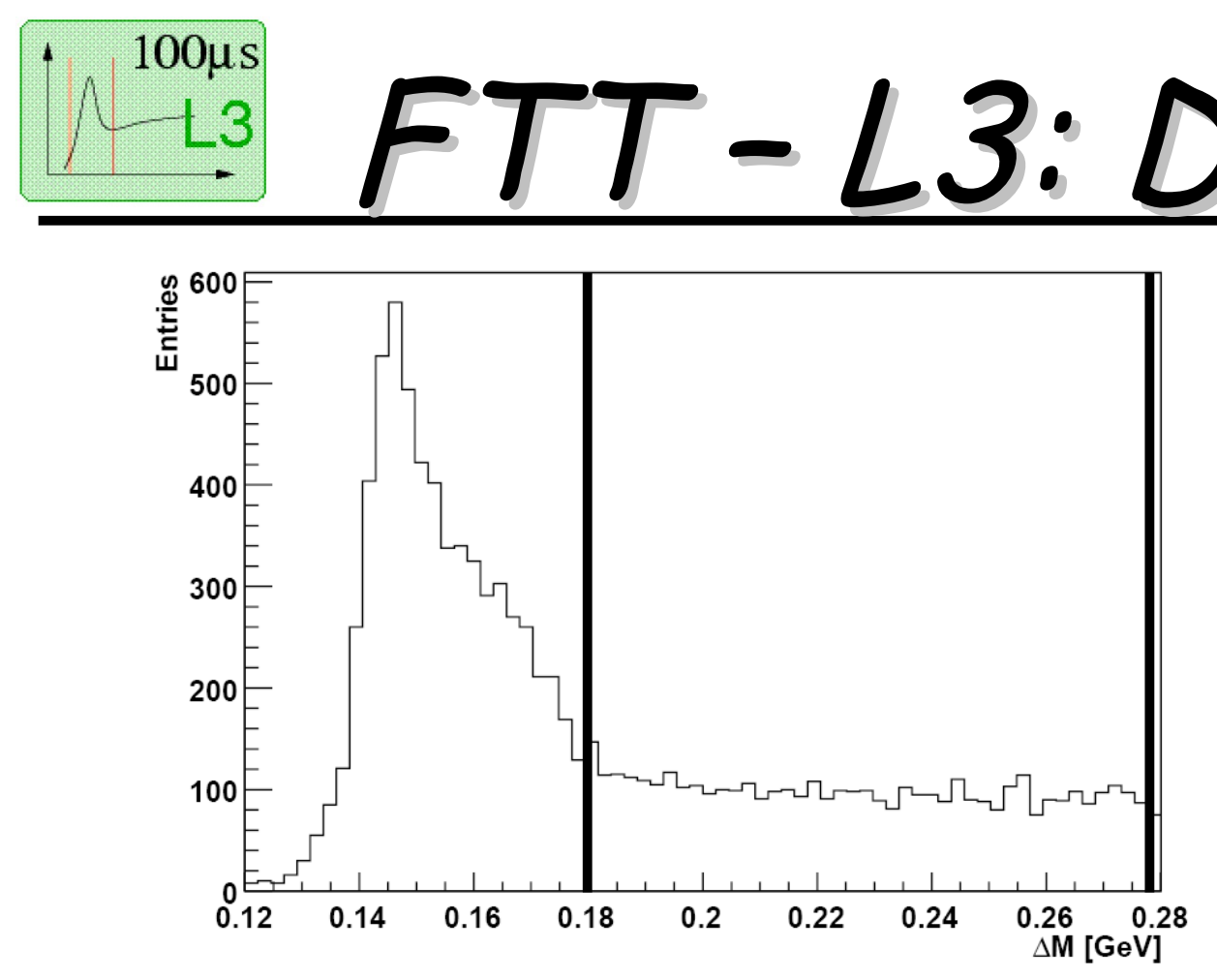

Select on:

- Cut on $\mathrm{P}_{\mathrm{T}, \mathrm{FT} T}$ Charge

- Invariant mass for: $D^{*}$ and $D^{0}$

- Cut on: $\quad \Delta \mathrm{M}=\mathrm{M}(\mathrm{K} \pi \pi)-\mathrm{M}(\mathrm{K} \pi)$

- Three triggers with:

$-\Delta M>180 \mathrm{MeV}, 280 \mathrm{MeV}$

$-P_{T, D^{*}}>1.5,2.5$ and $4.5 \mathrm{GeV}$

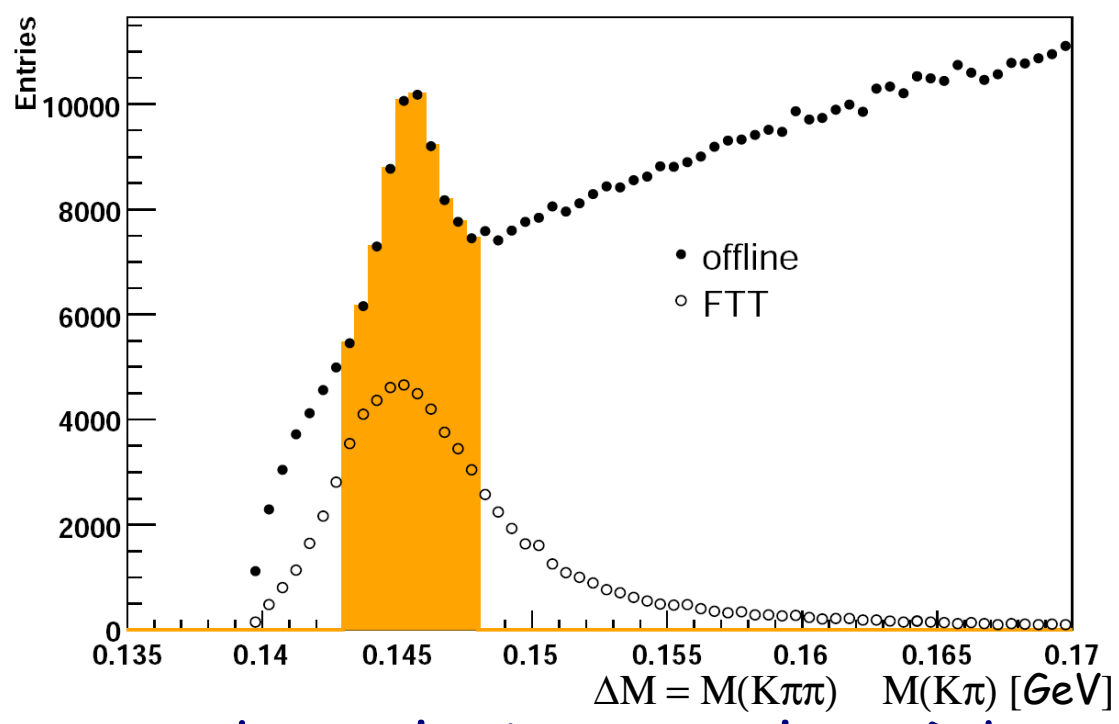

--> good resolution to select $D^{*} s$ on-line

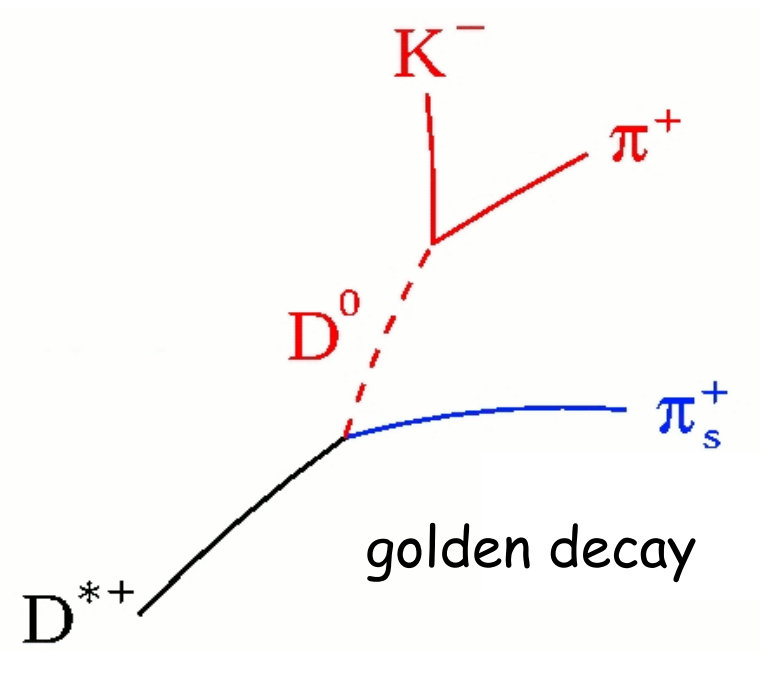

May $1^{\text {st }}, 2007$ First results from the $3^{\text {rd }}$ level of the H1 Fast Track Trigger (FTT) 
Rate reduction factors:

- 13 for low $p_{T, D^{*}}$

- 40 for medium $p_{T, D^{*}}$

- 60 for high $P_{T, D^{*}}$

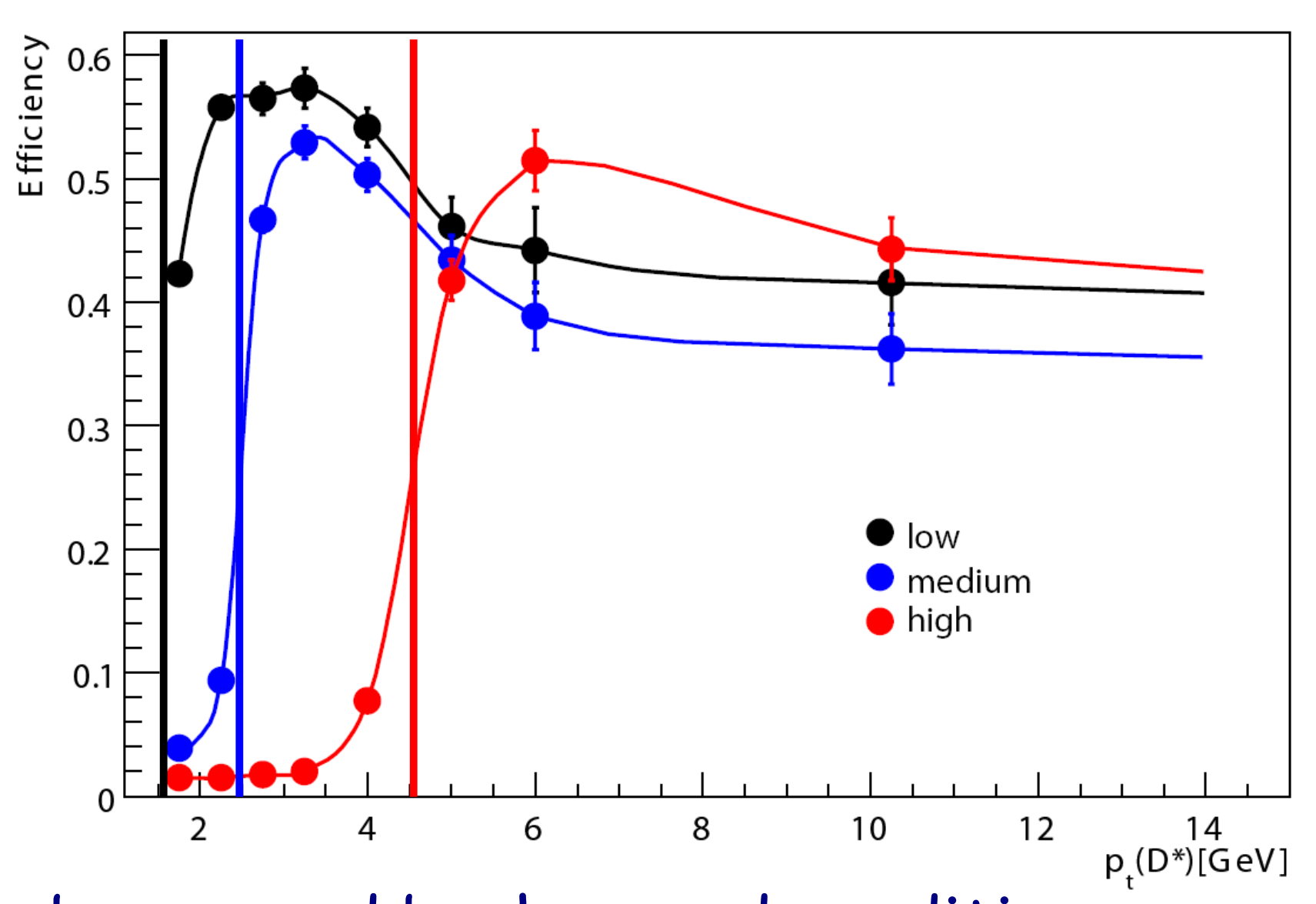

--> able to adjust for beam- and background conditions

$-\rightarrow$ best use of available rate budget 


\section{- 100urs \\ FTT - L3: First D* results}

"OR" of L3 D*-Trigger:

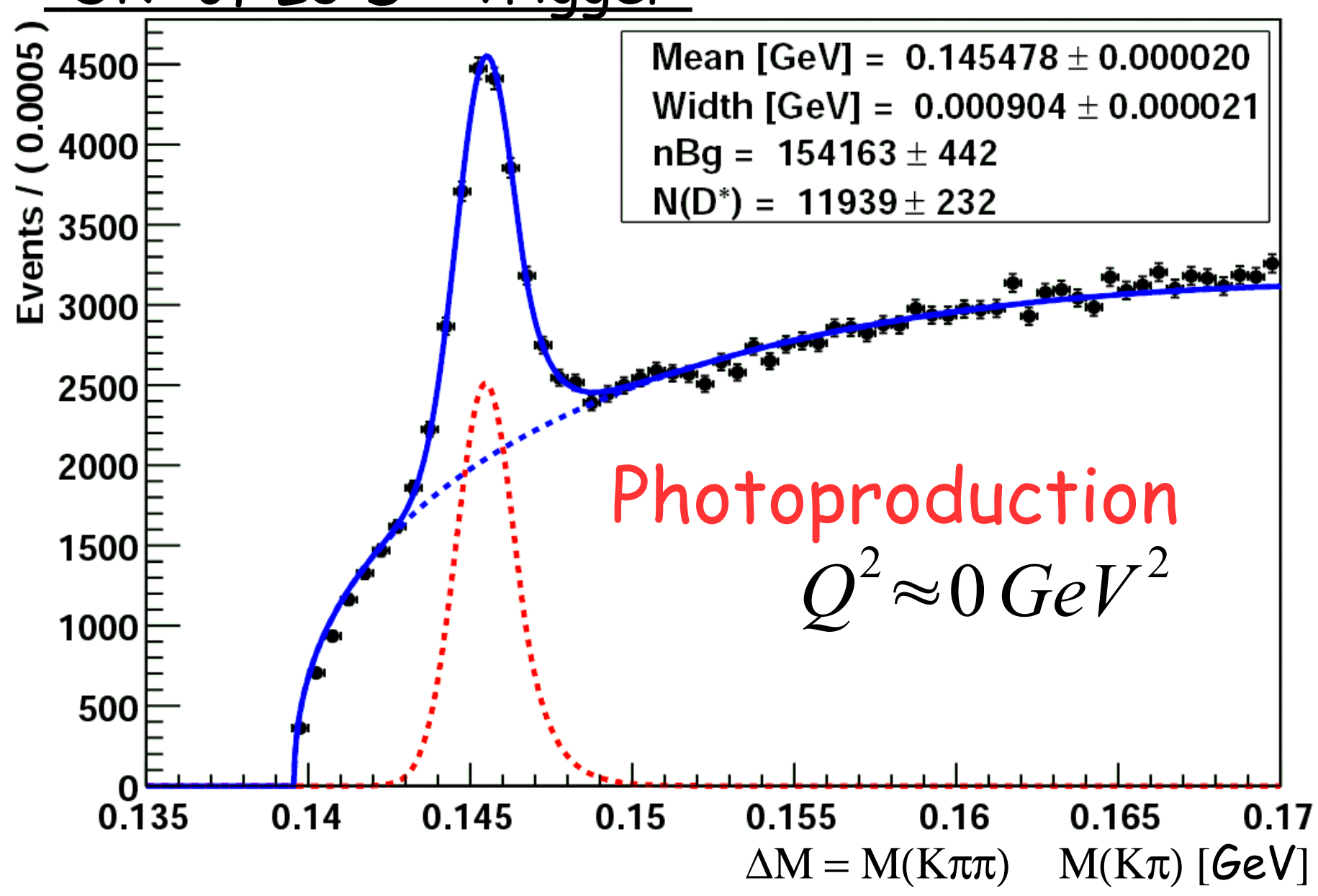

- Statistics increased by a Factor 10 compared to previous analysis (hep-ex/0608042)

- Large data samples for $D^{\star}$ - analysis

- Permits direct measurement of gluon density 


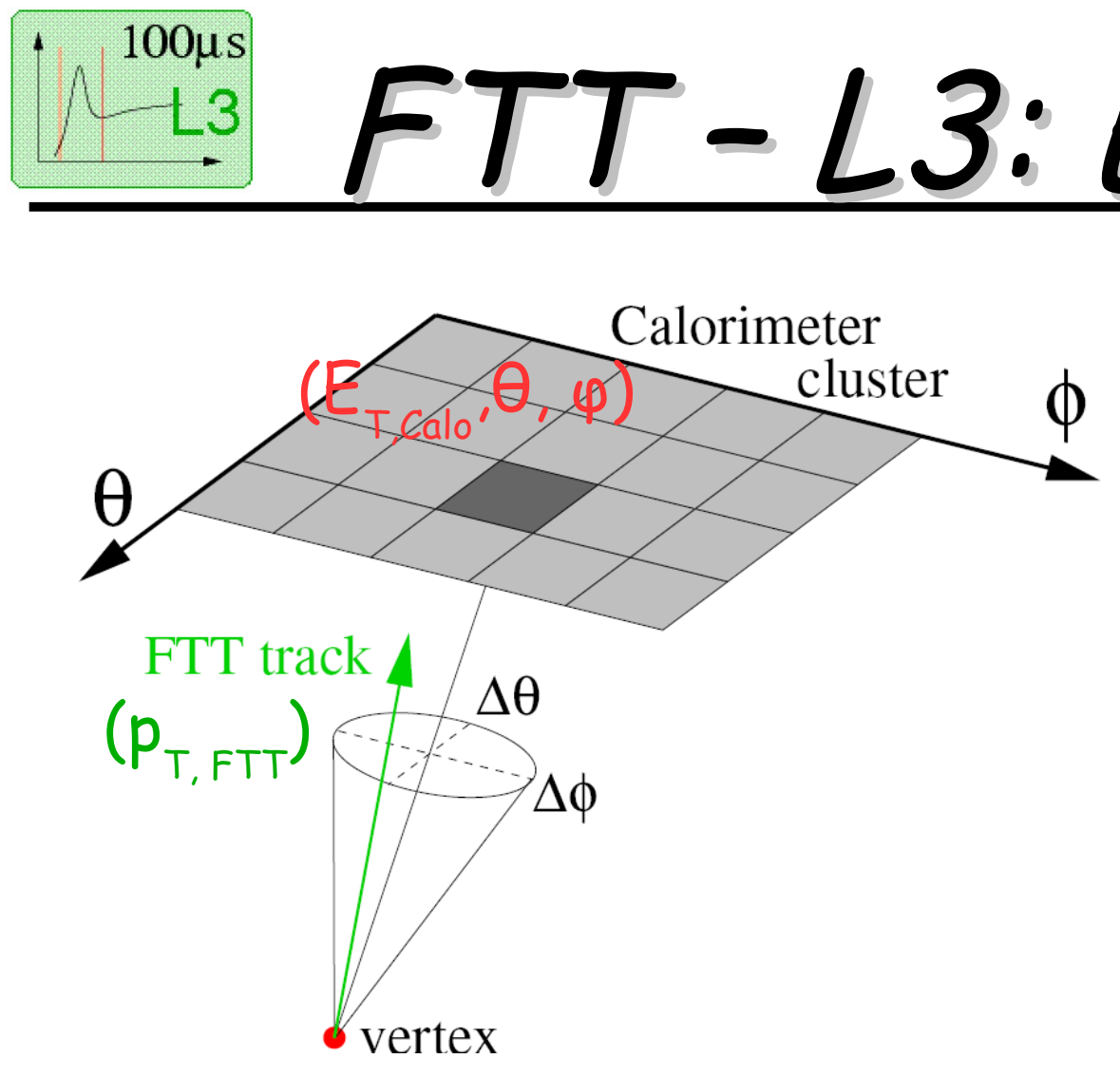

- Geometrical match: $\Delta \varphi, \Delta \theta$

- Kinematical match: $E_{T, \text { Calo }} / P_{T, \text { FTT }}$ (peak at $\sim 1$ for electrons)

- non-compensating Calorimeter: hadrons \& electrons separated

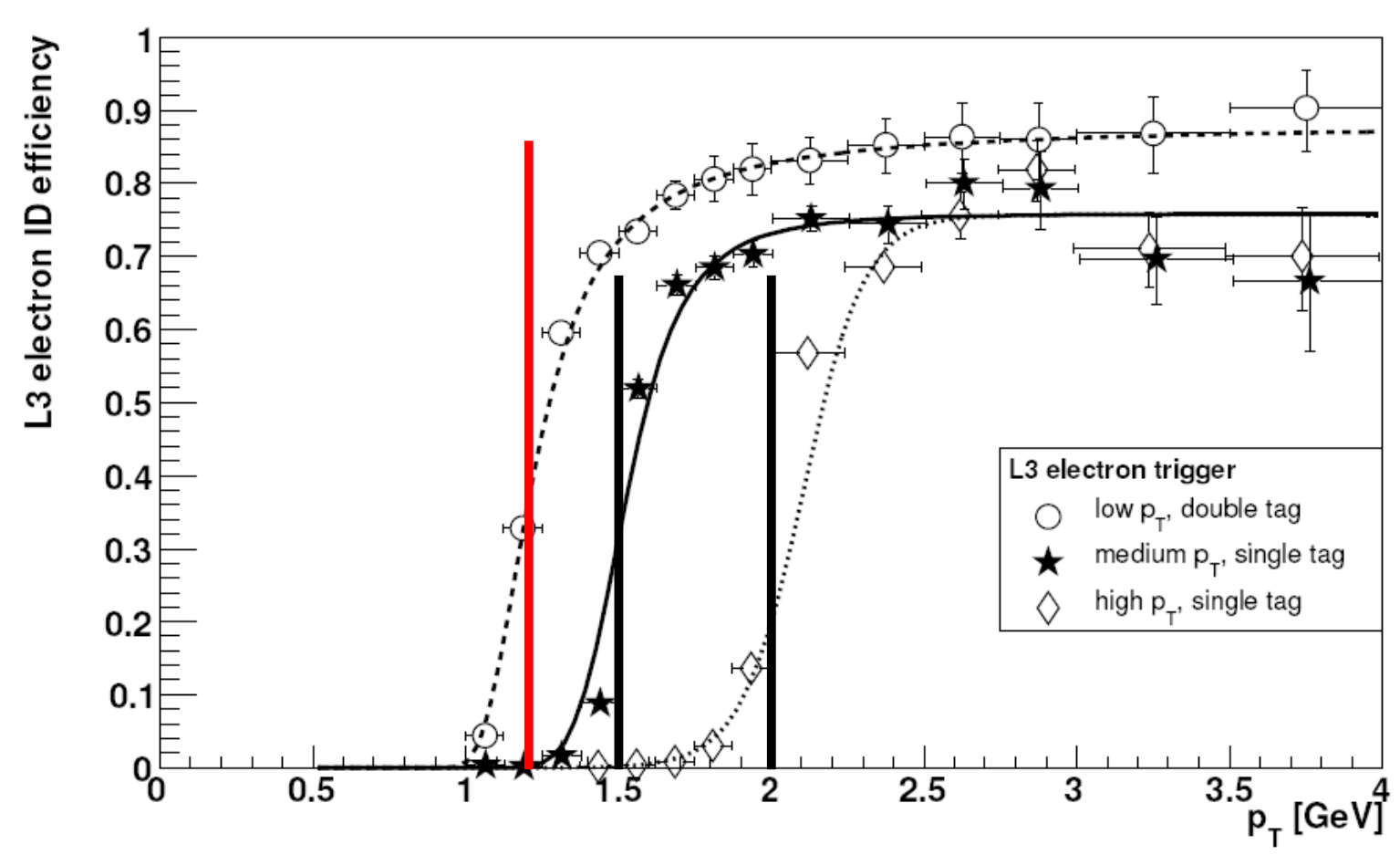

Focus: - electron ID at $p_{T}>1.2 \mathrm{GeV}$ (existing triggers: $p_{T}>5 G e V$ )

- rate reduction of $\sim 15-100$

- b-tagging for $b->e X$ 
Combination of muon trigger data and track information in L3:

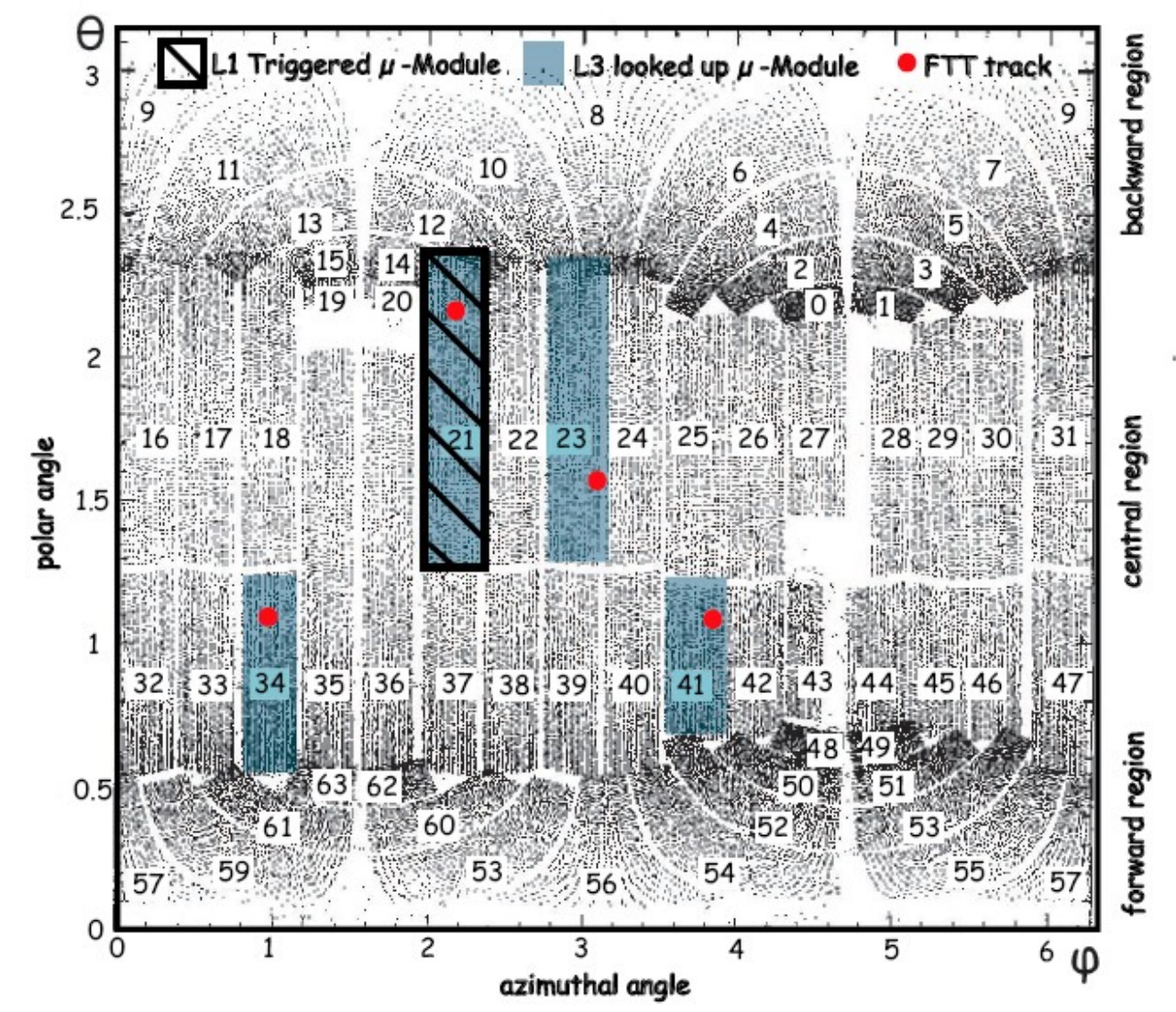

Provides:

- better rejection of:

- Cosmic muons

- Beam induced bg

\section{Efficiency for muon ID}

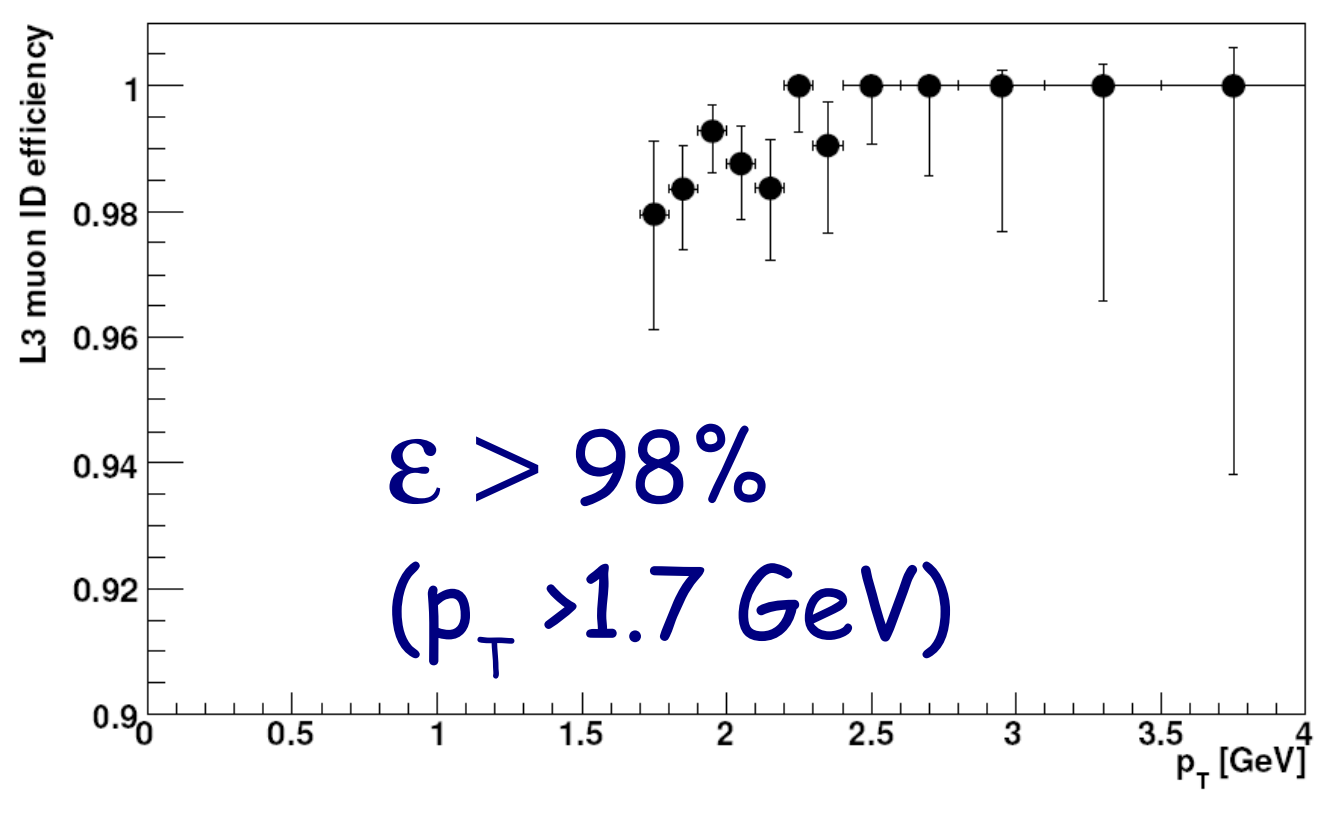

--> rate reduction factors of 3-10 achieved!

May $1^{\text {st }}, 2007$ First results from the $3^{\text {rd }}$ level of the H1 Fast Track Trigger (FTT) 


\section{Conclusion \& Outlook}

- The Fast Track Trigger - high selectivity \& rate reduction

- FTT-L3 since 2006 fully operational and good performance

- Trigger exclusive final states at low $p_{T}$

- Variety of new physics analysis possible
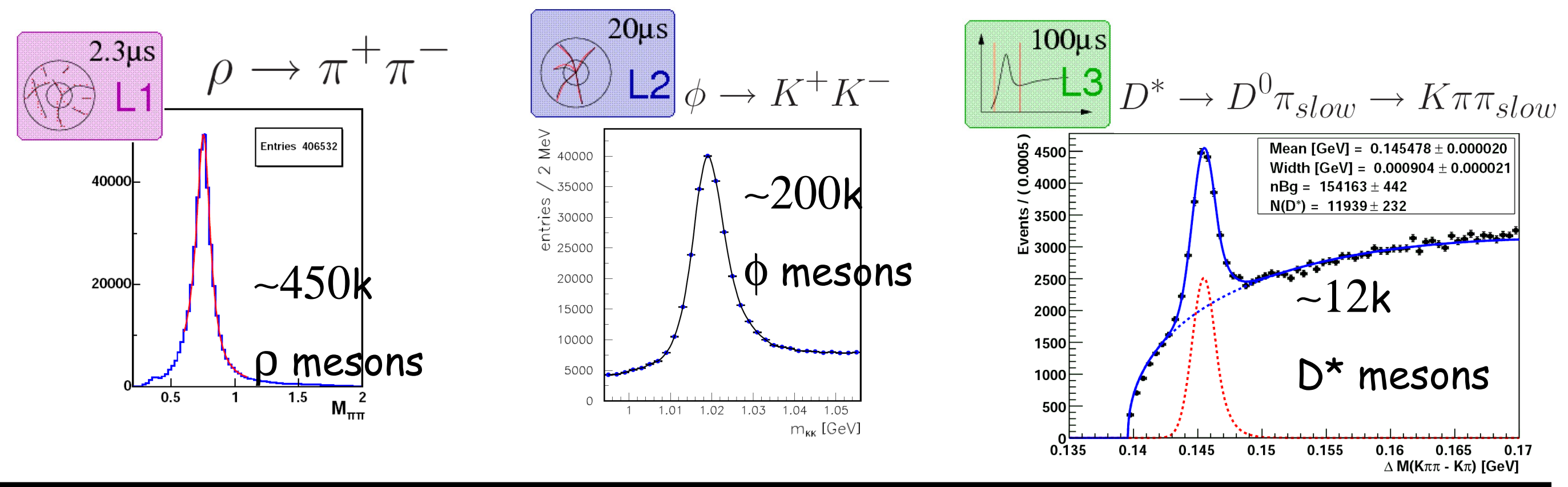

May $1^{\text {st }}, 2007$ First results from the $3^{\text {rd }}$ level of the H1 Fast Track Trigger (FTT) 


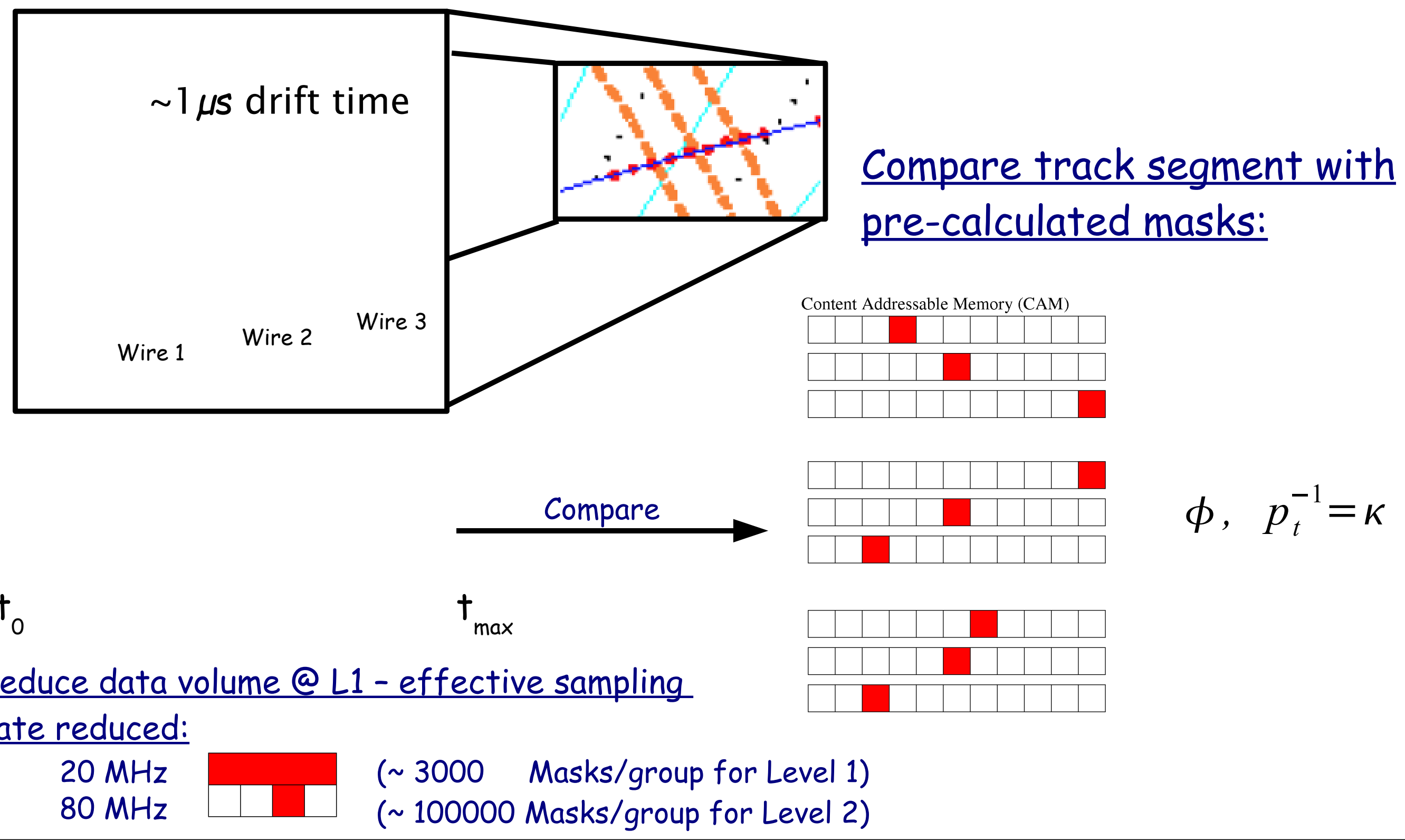


Level 1: - coarse $\kappa \varphi$-histogram with Level 2: - fine $\kappa \varphi$-histogram with
$16 \times 60$ bins

$40 \times 640$ bins

Track linking in 4 trigger layers: at least 2 out of 4 trigger layers

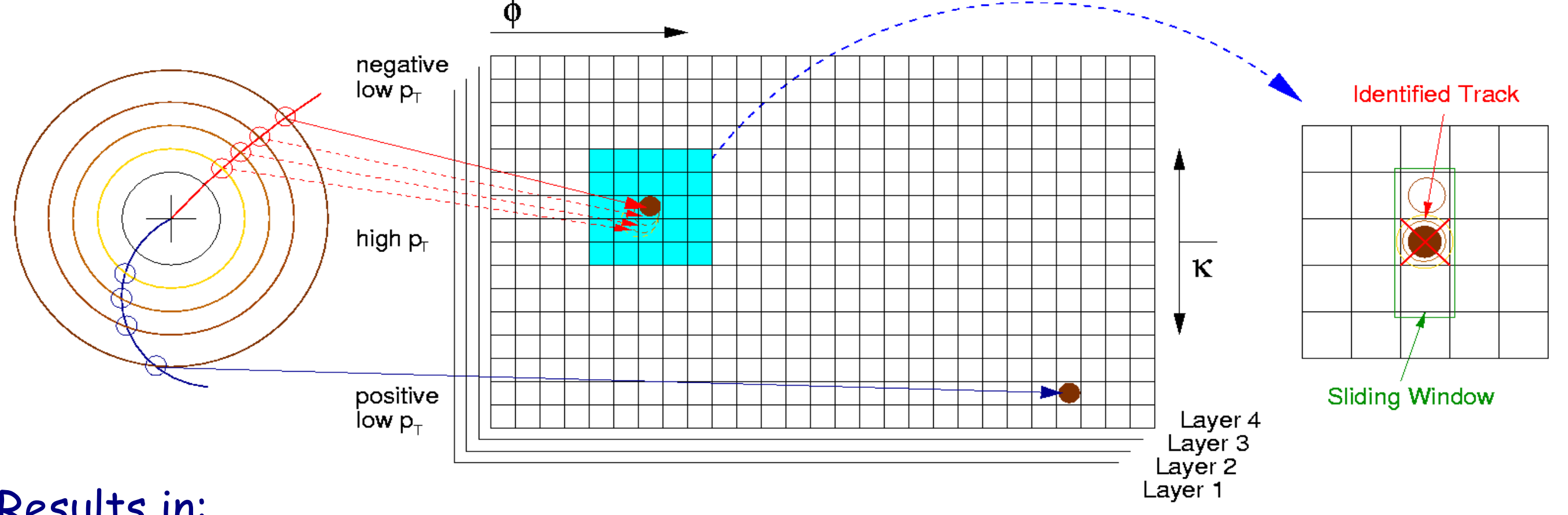

Results in:

- coarse L1- \& fine L2 tracks

$\rightarrow$ increase in precision with on-line track fit possible! 


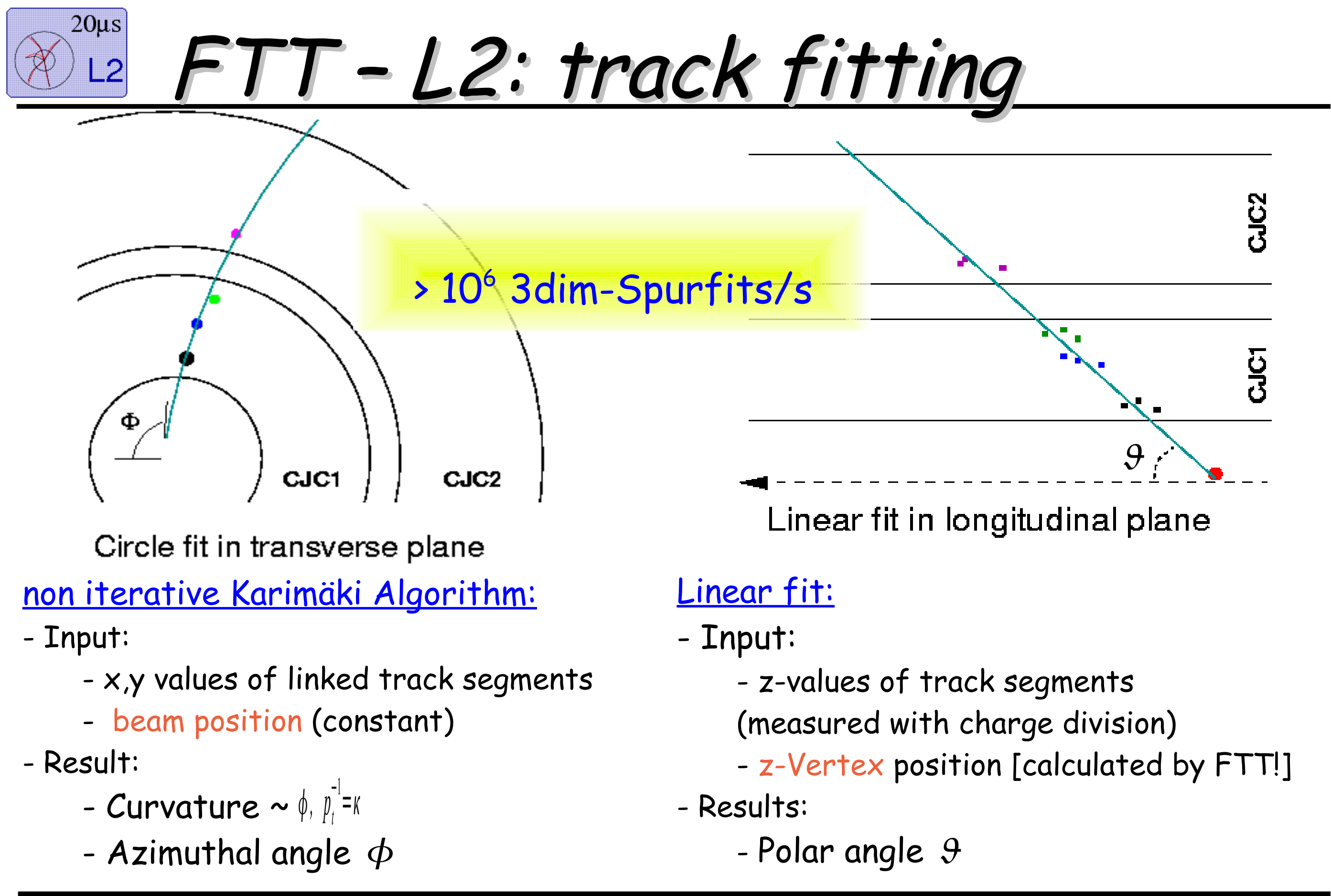




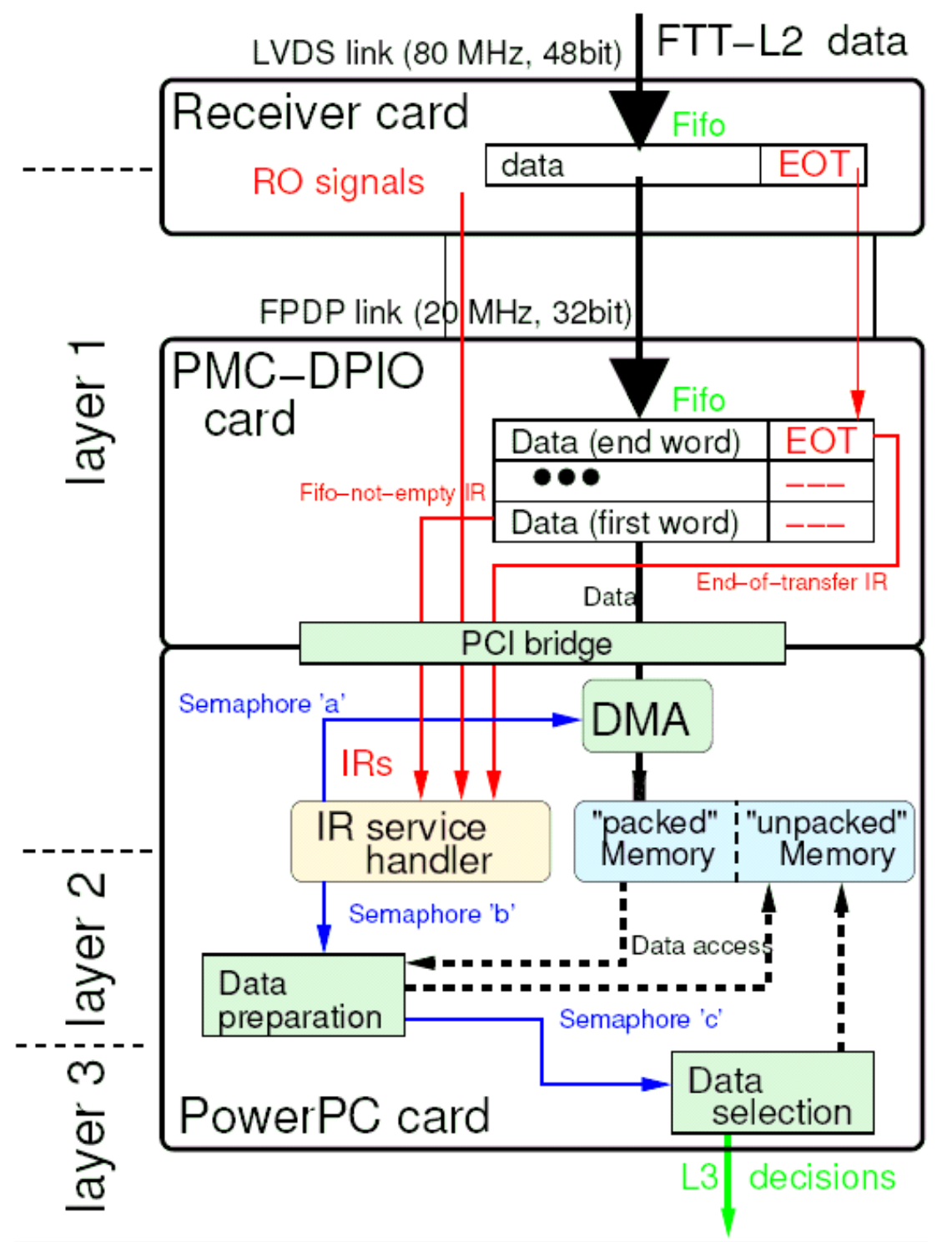

Trigger decision

Data preparation $<40 \mu \mathrm{s}$

Data transfer

$100 \mu s$
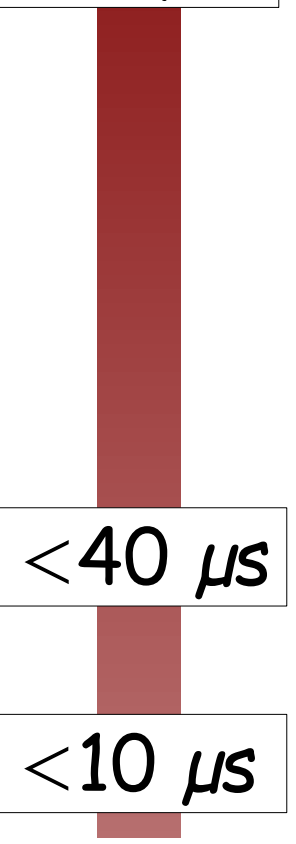

May $1^{\text {st }}, 2007$ First results from the $3^{\text {rd }}$ level of the H1 Fast Track Trigger (FTT) 


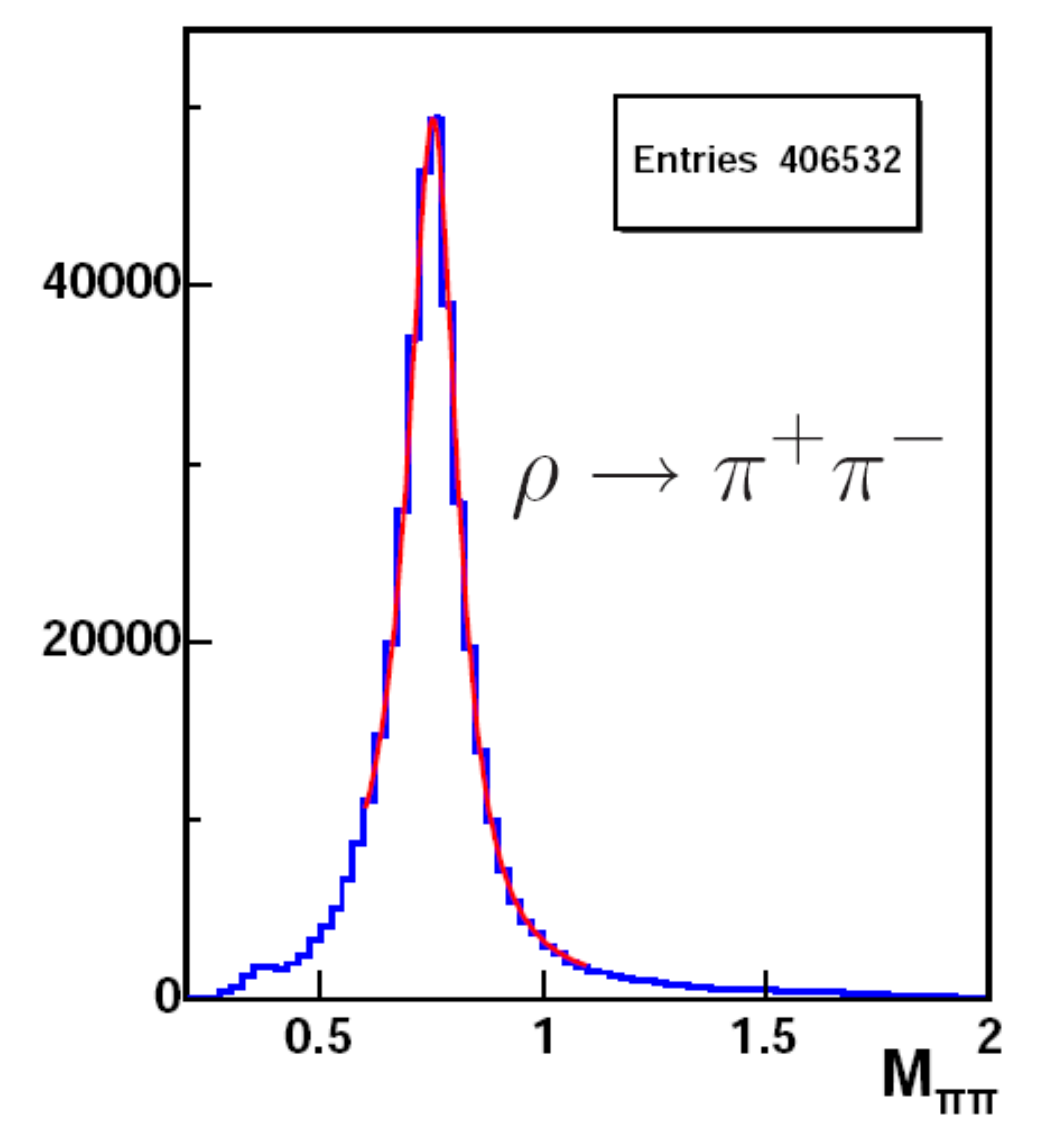

-> FTT-L1: Tracks with $P_{T}>100 \mathrm{MeV}$

\section{diffractive $\rho$ mesons:}

- 2 or 3 tracks with $p_{T}>100 \mathrm{MeV}$

- Opposite charge

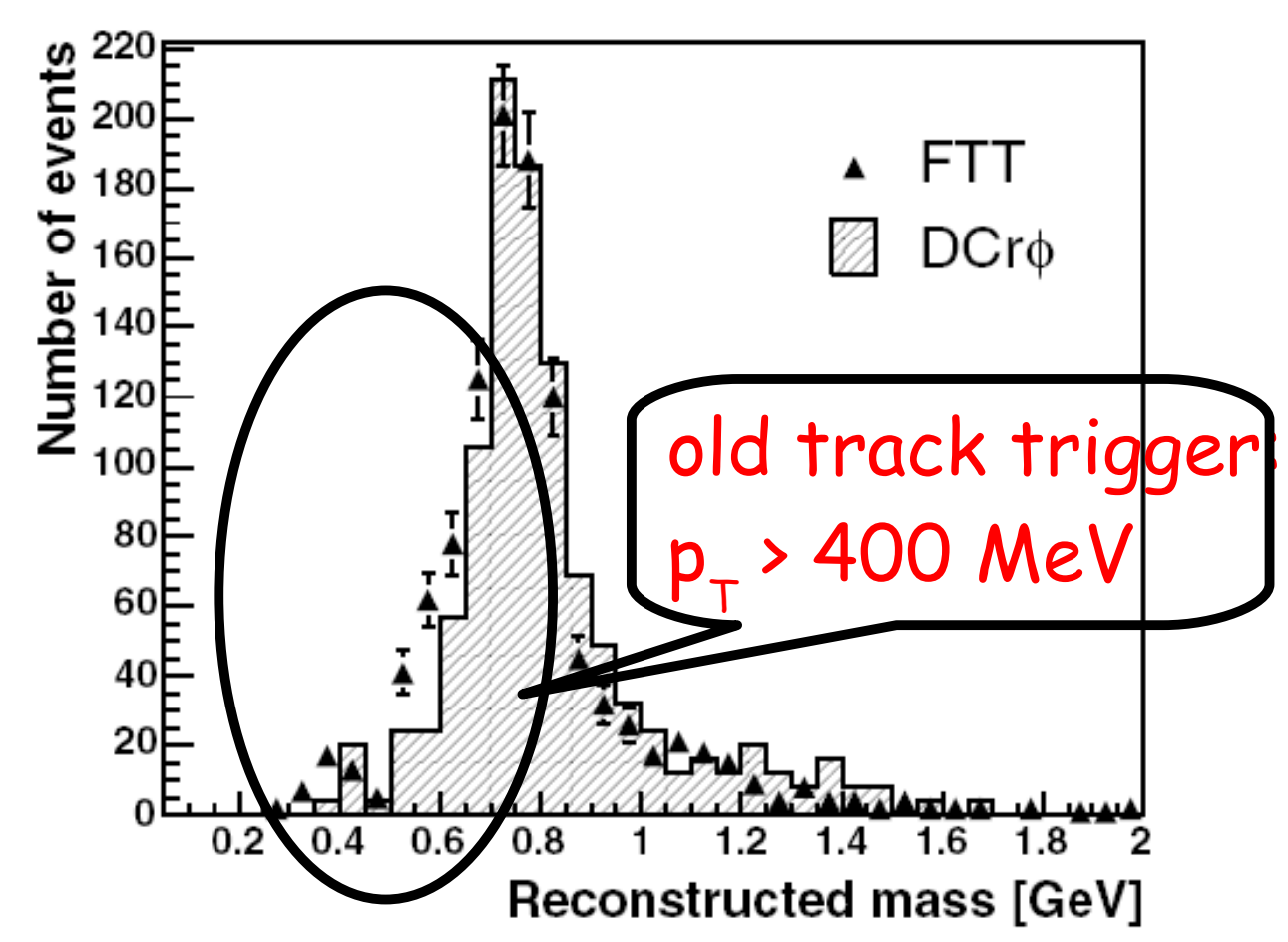




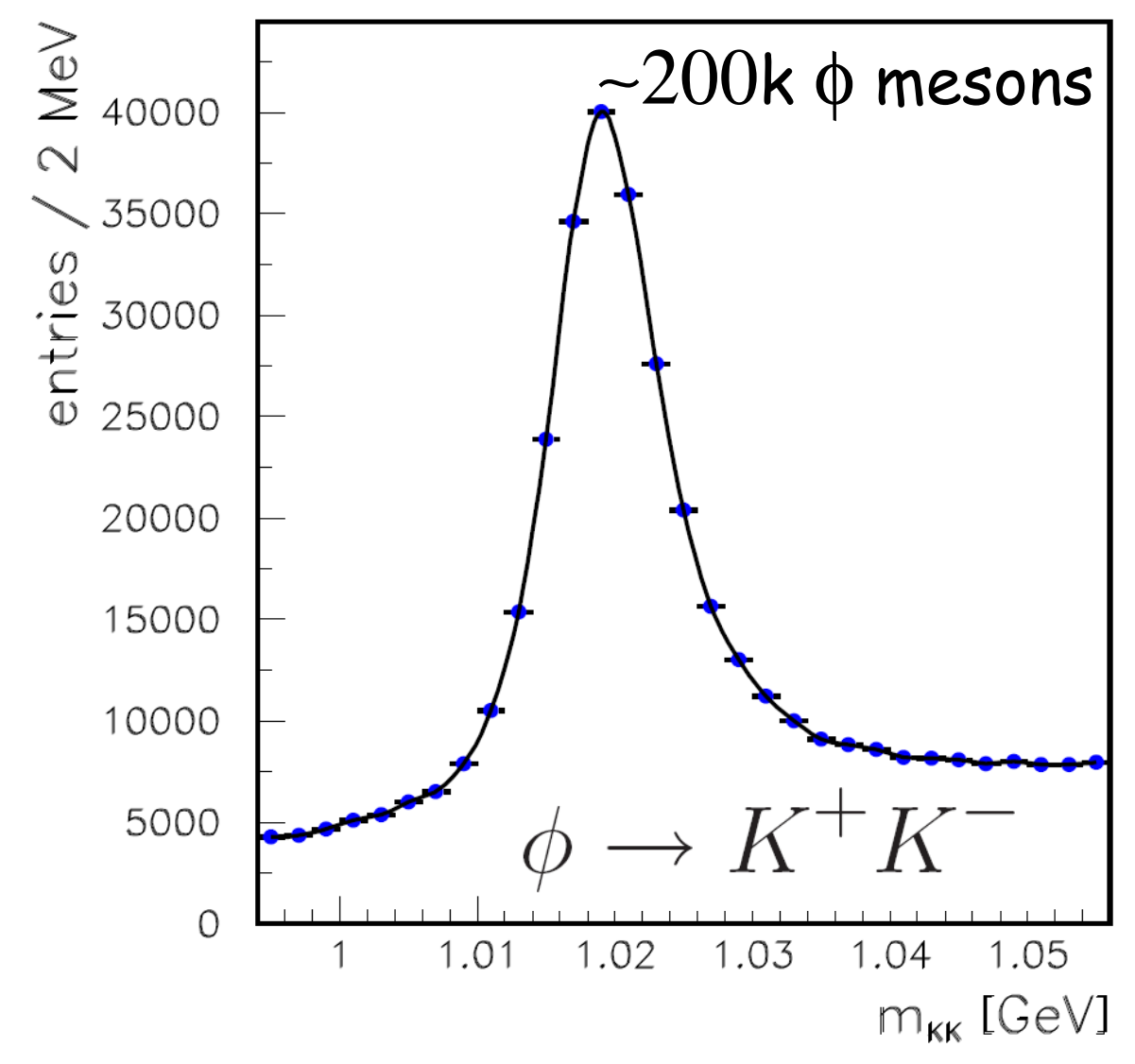

diffractive $\phi$ mesons:

- 2 or 3 tracks with $p_{\mathrm{T}}>100 \mathrm{MeV}$

- Opposite charge

- Tracks in adjacent sectors (use small opening angle)

-> FTT-L2: high precision track fit

because of $M(\phi)-M(K K) \sim 40 M e V \rightarrow$ $K$ small $p_{T}$ relative to

"direction of flight" of $\phi$

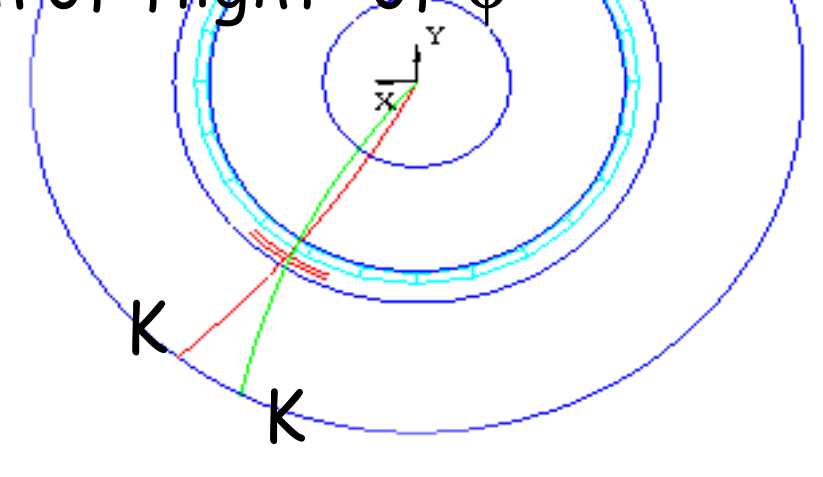




\section{FTT-L3: Electron ID eff.}

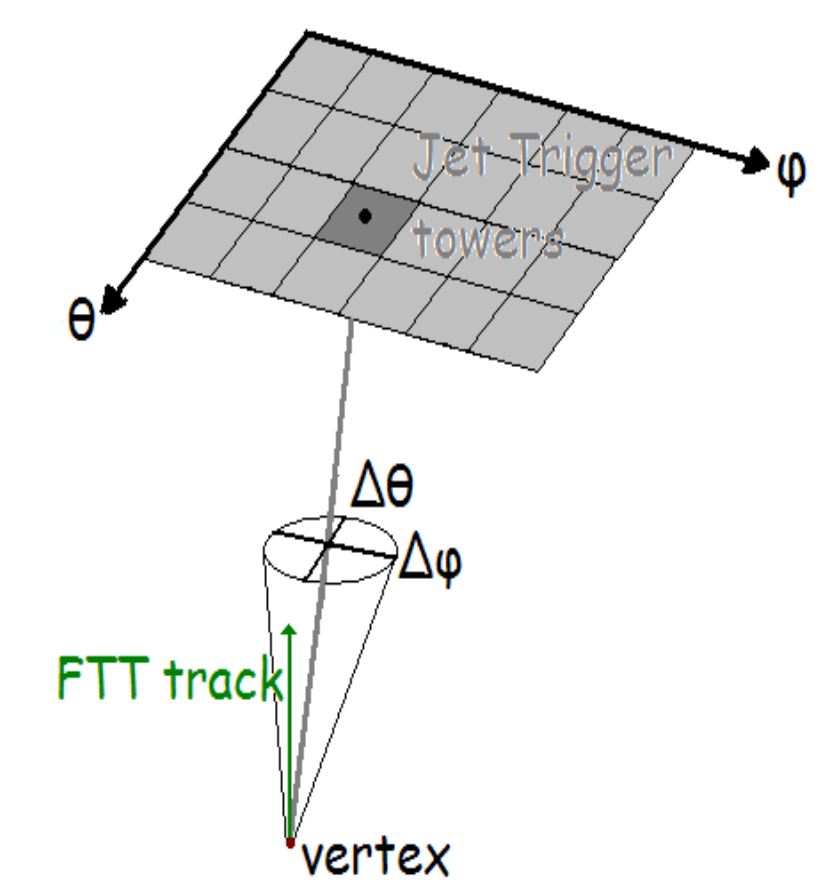

Combination of Calorimeter energy depositions $\left(E_{T, \text { Calo }}, \theta, \varphi\right)$ and track information $\left(\mathrm{P}_{T, F T T}\right)$ :

$\bullet p_{T, F T T}>p_{T, \text { cut }}$

$-\Delta \varphi<\varphi_{\text {cut }}$ (FTT $\varphi$ is corrected for curvature)

$\cdot \Delta \theta<\theta$

- $E_{T T} / P_{T, F T T}$ (peaks around 1 for electrons due to the non compensating calorimeter)
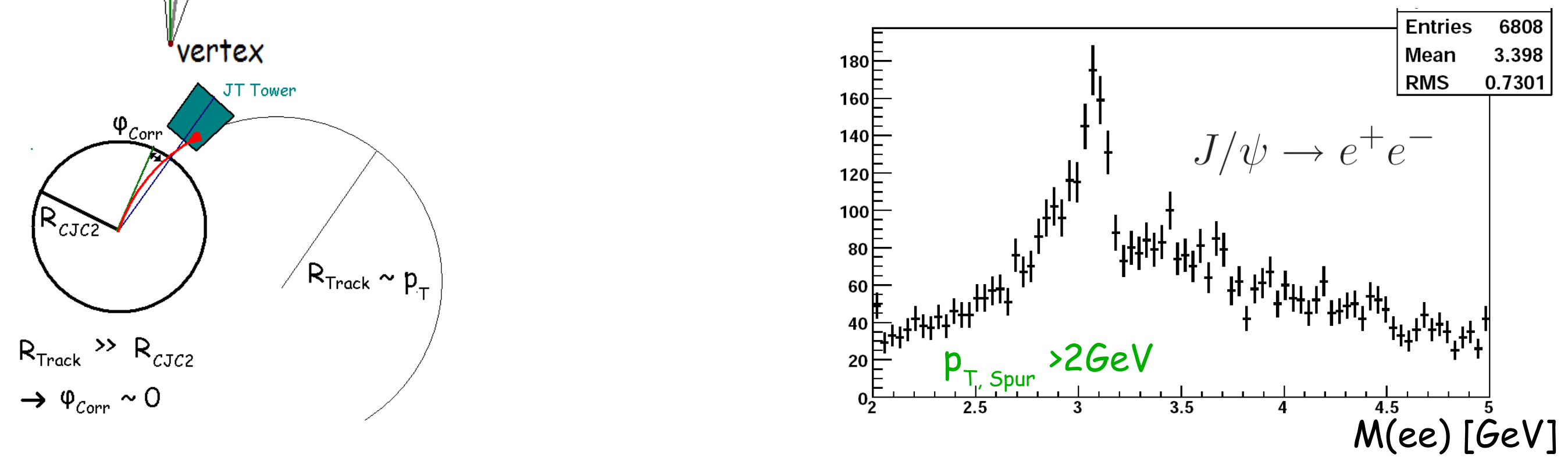

May $1^{\text {st }}, 2007$ First results from the $3^{\text {rd }}$ level of the H1 Fast Track Trigger (FTT) 